\title{
Heterogeneity in barriers regarding the motivation, the opportunity and the ability to choose low-calorie snack foods and beverages: associations with real-life choices
}

\author{
Colin Bos ${ }^{1, *}$, Ivo A van der Lans ${ }^{1}$, Frank J van Rijnsoever ${ }^{2}$ and Hans CM van Trijp ${ }^{1}$ \\ ${ }^{1}$ Marketing and Consumer Behaviour Group, Wageningen University, Hollandseweg 1 (5019), 6706 KN \\ Wageningen, The Netherlands: ${ }^{2}$ Innovation Studies, Copernicus Institute of Sustainable Development, \\ Utrecht University, Utrecht, The Netherlands
}

Submitted 10 March 2015: Final revision received 10 July 2015: Accepted 22 July 2015: First published online 2 September 2015

\begin{abstract}
Objective: Employing Rothschild's Motivation-Opportunity-Ability framework, the present study examines the extent to which heterogeneity in barriers regarding the motivation, the perceived opportunity and the perceived ability to choose low-calorie over high-calorie snacks is associated with the proportion of lowcalorie snack choices in real life. Furthermore, the study investigates which dominant barrier profiles can be discerned.

Design: Data were obtained from a survey about participants' motivation, opportunity and ability to choose low-calorie over high-calorie snacks and an FFQ that measured habitual consumption of snack foods and beverages. Data were analysed using R packages lavaan and NbClust, and IBM SPSS Statistics. Setting: A representative sample ( $n$ 1318) of the Dutch population based on gender (686 women), age and education level.

Results: For both snack foods and beverages, motivation to choose low-calorie over high-calorie snacks was associated strongest with proportions of low-calorie choices. The perceived ability and perceived opportunity were also associated with proportions of low-calorie choices, albeit to a lesser extent. Furthermore, three dominant profiles of barriers were identified: the no-barrier profile, the lackof-opportunity profile and the lack-of-motivation profile. These profiles differed significantly on proportions of low-calorie snack choices, daily meal consumption and sociodemographic characteristics.

Conclusions: Heterogeneity in barriers regarding the motivation, the perceived opportunity and the perceived ability to choose low-calorie over high-calorie snacks is associated with the proportion of low-calorie snack choices in real life. By identifying and appreciating heterogeneity in barriers, the present study provides further incentives for the tailoring of intervention strategies.
\end{abstract}

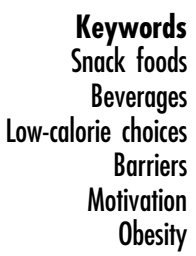

A worrying rise of overweight and obesity rates, accompanied by related chronic and non-communicable diseases, continues to threaten public health around the world $^{(1)}$. The origin of overweight and obesity lies primarily in an imbalance between the intake and the expenditure of energy ${ }^{(2)}$. During the last decades there has been an increase in daily eating occasions ${ }^{(3)}$ and therewith daily energy intake has also increased.

The excess energy intake is primarily a consequence of a change in snack consumption ${ }^{(3)}$. In the USA, energy intake through regular meals increased slightly from 1977 to 2006 (8\%), while the energy intake through snacks more than doubled $(130 \%)^{(3)}$. Similar trends have been detected in
Europe $^{(4,5)}$. Since energy expenditure decreased only slightly over the same period ${ }^{(2)}$, the obesity problem is best described as an issue of systematic caloric overconsumption ${ }^{(6)}$, with snacking as an increasingly important contributor.

Literature on the relationship between weight status and snacking behaviour is inconclusive ${ }^{(7)}$. This can partly be explained by the fact that weight status is not only influenced by snacking but also by factors such as meal consumption and physical activity. Furthermore, these factors are interrelated, as sometimes people eat a snack as meal replacement or because of some heavy physical activity. At a methodological level, an additional reason might be the lack of consensus on the definition of snacking. 
This makes it difficult to establish a relationship, since conclusions about the association between obesity and snacking are heavily dependent on how snacks and snacking behaviour are defined ${ }^{(7,8)}$. The present study therefore adapts the proposed universal definition of snacks by Johnson and Anderson ${ }^{(7)}$ : everything that is consumed outside the regular meals (breakfast, lunch and dinner) and is not a substitute for a meal.

Whether snacking is detrimental to one's weight status depends on the caloric values of frequently consumed snacks. In itself snacking does not necessarily promote weight gain, because low-calorie snacks that supplement a balanced and healthy diet are available ${ }^{(9)}$. However, most foods and drinks that are consumed outside the regular meals are high in calories ${ }^{(10)}$. To effectively stimulate low-calorie snacking, insight into the determinants of choosing snacks that are low in calories over snacks that are high in calories is crucial.

The present study employs Rothschild's MotivationOpportunity-Ability (MOA) framework ${ }^{(11)}$ and examines the extent to which heterogeneity in barriers regarding the motivation, the perceived opportunity and the perceived ability to choose low-calorie over high-calorie snacks is associated with the proportion of low-calorie snack choices in real life. We expect that on a theoretical level the association between barriers and real-life choices is generalizable across snack categories, even though some research suggests that differences in barriers for low-calorie choices within these snack categories might exist ${ }^{(12)}$. To test generalizability across snack categories, barriers and real-life choices are assessed separately for snack foods and beverages. Furthermore, the study investigates whether subgroups of people with similar barrier profiles can be found. Identification of dominant barrier profiles enables tailoring of intervention strategies, which has been shown to be beneficial for both the acceptance and effectiveness of interventions $^{(13,14)}$

\section{Theoretical background}

Snack choices are an element of the total spectrum of food choices. Hence, to gain insight into the determinants of choosing low-calorie over high-calorie snacks, we build from the literature on food choices in general. Food choices are frequent, multifaceted, situational, dynamic and complex ${ }^{(15)}$, and therefore reasons for choosing certain foods vary between people. We now provide a short overview of two categories of behavioural determinants that are important for food choices: individual-level and environmental determinants.

Several behavioural theories that have been applied to dietary behaviours, such as the Theory of Planned Behaviour $^{(16)}$, the Health Belief Model ${ }^{(17)}$ and the TransTheoretical Model ${ }^{(18)}$, recognize evaluations of expected outcomes of behaviour as key determinants for food choices. These evaluations, referred to as 'attitudes' in the Theory of Planned Behaviour, can be divided into cognitive and affective attitudes ${ }^{(19)}$. Cognitive attitudes are evaluations of expected utilitarian outcomes of dietary behaviours (e.g. 'I think eating low-calorie snacks is healthy'), whereas affective attitudes reflect evaluations of expected hedonic outcomes of choosing certain foods (e.g. 'I think eating low-calorie snacks is boring'). When people's cognitive and affective attitudes towards choosing certain foods are negative, they will be less likely to choose these foods ${ }^{(20-22)}$. In addition, the Theory of Planned Behaviour claims that normative beliefs regarding dietary behaviour are also important.

Most behavioural theories furthermore acknowledge that perceptions about having sufficient skills and knowledge to perform a behaviour (Health Belief Model and Trans-Theoretical Model: 'self-efficacy'; Theory of Planned Behaviour: (perceived behavioural control') influence the likelihood of execution of that behaviour (e.g. 'I am confident that I can differentiate between low-calorie and high-calorie snacks'). When people feel that they lack these abilities, and thus have a low self-efficacy, they are less likely to engage in the behaviour ${ }^{(23,24)}$.

In contrast to behavioural theories that highlight individual-level influences, Social Ecological Models ${ }^{(25)}$ emphasize environmental factors that drive food choices. The ANGELO (ANalysis Grid for Elements Linked to Obesity) framework ${ }^{(26)}$, which has been specifically designed to conceptualize food-choice environments, distinguishes between physical, economic and media environments. For the physical environment, research has shown that changes in the physical accessibility and availability of foods have a great impact on food-choice behaviour ${ }^{(27,28)}$. And although causality is unclear, studies that focused on people's perceptions of food-choice environments found that a higher perceived physical availability of energy-dense foods is associated with a higher intake of these foods ${ }^{(29-32)}$. Additionally, food-choice experiments have shown that the economic environment heavily influences food choices ${ }^{(33,34)}$. This is in line with research based on interviews and focus groups, where costs of foods and beverages are often mentioned as barriers and triggers for consumption ${ }^{(35,36)}$. Lastly, the association between the media environment and food choices has often been suggested in scientific literature, mostly by linking advertising for unhealthy foods to obesity $^{(37,38)}$. Evidence for the influence of the physical, economic and media environment on food choices has accumulated over the past years, thereby implying that increasing obesity rates are primarily a result of an 'obesogenic environment' that promotes overeating ${ }^{(39,40)}$.

Summarizing, behavioural theories that have been applied to dietary behaviours show that both individuallevel and environmental determinants drive food-choice behaviour. Rothschild's MOA framework ${ }^{(11)}$ encompasses the heterogeneity in determinants by stressing the significance of both individual-level and environmental 
influences on behaviour. The MOA framework integrates the core concepts of the Theory of Planned Behaviour and Social Ecological Models, which in combination have been identified as the most promising models for obesity prevention $^{(41)}$.

Applied to the food-choice context, the framework theorizes that when motivation, opportunity and ability for a certain dietary behaviour are sufficiently present, people will likely execute the behaviour. A lack of motivation, opportunity and/or ability, however, functions as a barrier for behaviour. More specifically, a lack of motivation results in a resistance to behave, whereas the lack of opportunity and ability result in an inability to behave.

Rothschild's MOA framework poses that there is heterogeneity in barriers towards desirable behaviour, i.e. people differ regarding the extent to which they experience the various barriers. It structures this heterogeneity by distinguishing between a total of eight different profile types based on the presence or absence of barriers within MOA (Motivation: barrier/no barrier $\times$ Opportunity: barrier/no barrier $\times$ Ability: barrier/no barrier). The framework then argues that, depending on the dominant barrier profiles, intervention strategies based on education (for Ability-related barriers), marketing (for Opportunity-related barriers) and/or law (for Motivation-related barriers) should be used to diminish barriers for behaviour.

The present study consists of two parts. The first part relates heterogeneity in barriers in motivation, perceived opportunity and perceived ability to the proportion of lowcalorie snack choices in real life. The second part examines which and how many of the eight MOA profile types, as suggested by Rothschild, are most prevalent. Public health policies greatly benefit from identification of actionable subgroups with similar barrier characteristics, as providing tailored interventions to each individual is infeasible. By identifying these dominant MOA profiles, recommendations regarding intervention strategies can be made.

\section{Methods}

\section{Procedure and sample}

An online survey, comprising of two waves, was conducted. Wave 1 was divided into two parts (presented in a random order): one part focused on individuals' motivation, opportunity and ability to choose low-calorie over high-calorie snack foods, while the other part focused on beverages. During the instructions of Wave 1, respondents were given the following information: 'Low-calorie snacks contain relatively few calories. For instance fruits and rice waffles/water and light soft drinks. High-calorie snacks contain relatively many calories. For instance crisps and pie/chocolate milk and regular soft drinks'. Four weeks later the second wave of data was collected, which consisted of an FFQ specifically aimed at snack foods and beverages. Both in the first and second wave respondents were instructed to think of snacks as being 'all foods and beverages that are consumed outside breakfast, lunch and dinner'. Splitting up the data collection into two waves was done to prevent respondent burden and the four-week intermission was employed to minimize consistency bias.

Data were collected in the Netherlands by the commercial marketing research agency GfK. GfK provided a representative sample of the Dutch population based on gender, age and education level, which was recruited from the Gf K Online Panel. The incentive to participate was a number of 'GfK points' for which coupons can be ordered (equivalent to about $5 €$ ). Of the 1573 respondents who completed Wave 1 , a total of 1318 completed Wave 2. Response rates were $70 \%$ and $84 \%$, respectively. Characteristics of these 1318 respondents are summarized in Table 1.

\section{Measures}

Motivation, opportunity and ability to choose low-calorie over high-calorie snacks

Because the MOA framework itself does not dictate how the MOA constructs should be measured, we used and adapted scales from existing scales from the behavioural theories ${ }^{(42,43)}$ as much as possible. When appropriate scales were lacking, we constructed them on the basis of previous qualitative research ${ }^{(13,44)}$. A complete list of items is provided in the online supplementary material.

For measuring Motivation, participants' attitudes, personal norms and social norms towards choosing lowcalorie over high-calorie snacks were assessed. Cognitive and affective attitudes towards choosing low-calorie over high-calorie snacks were measured by means of eight 7-point semantic differential scale items, which were adapted from Conner et al. ${ }^{(21)}$ and Crites et al. ${ }^{(19)}$. Personal norms regarding choosing low-calorie over high-calorie snacks were assessed by three items, adapted from Parker et $a l .{ }^{(45)}$. Social norms were measured with one item that was adapted from Conner et al. ${ }^{(21)}$.

For measuring Opportunity to choose low-calorie over high-calorie snacks ten items were constructed. The items were based on previous qualitative research ${ }^{(13,44)}$ and were structured according to the ANGELO framework ${ }^{(26)}$, which differentiates between the physical, economic and media environment in which food choices are made. Using this subdivision of environments, participants' perceptions of the physical and economic environments were assessed with four items each. Additionally, two items represented perceptions of the media environment.

For measuring Ability, participants' self-efficacy with regard to having the basic skills and knowledge to choose low-calorie over high-calorie snacks was assessed. These basic skills and knowledge were identified in a previous qualitative study ${ }^{(13)}$. For knowledge, we constructed four items that assessed the perceived ability to distinguish between low-calorie and high-calorie products. Skills to 
understand calorie information on packages were assessed with one item. The formulation of the self-efficacy items was adapted from Sheeshka et al. ${ }^{(46)}$.

The surveys were pre-tested during cognitive walkthrough interviews ( $n$ 5). Based on these pre-tests, improvements in the formulation of items were made. The revised surveys were then piloted online ( $n$ 50). Based on similar feedback from four respondents, two minor changes were made regarding the qualification of behavioural ability to assess calorie content from 'well' to 'accurately'. Because this was the only feedback on item formulation from the pilot study, we judged the final questionnaire items to be adequately formulated.

\section{FFQ and main meal consumption}

To assess real-life snack choices, an FFQ was administered. The questionnaire was carefully developed with the considerations regarding the construction of FFQ in mind ${ }^{(47)}$. Participants indicated how often they normally choose specific types of snacks: less than once per month/never (coded as 0 times/week), 1-3 times per month (coded as 0.5 times/week), 1-3 times per week (coded as 2 times/week), 4-6 times per week (coded as 5 times/week), daily (coded as 7 times/week) and several times per day (coded as 14 times/week). The snack foods and beverages that were included were identified as frequently consumed snacks in previous research ${ }^{(13)}$. For low-calorie snack foods these were (fruit) biscuits, small candy bars, gingerbread, water ice, soup, crackers and fruit; for high-calorie snack foods these were cake, cookies, regular candy bars, chocolate, pie, ice cream, warm snacks, nuts, crisps and sandwiches. Low-calorie beverages consisted of coffee, tea, (flavoured) water, fruit juice light, soft drink light and malt/light beer; high-calorie beverages consisted of cappuccino, chocolate milk, fruit juice regular, soft drink regular, milk, yoghurt drink, regular beer, wine and liquor. Items were classified as low-calorie when a portion was $<418.4 \mathrm{~kJ}(<100 \mathrm{kcal})$ and high-calorie when a portion was $>418.4 \mathrm{~kJ}(>100 \mathrm{kcal})$,

Table 1 Characteristics of respondents, a representative sample ( $n$ 1318) of the Dutch population based on gender, age and education level

\begin{tabular}{|c|c|c|}
\hline & Males ( $n$ 632) & Females ( $n$ 686) \\
\hline \multicolumn{3}{|l|}{ Age (\%) } \\
\hline $18-34$ years & $26 \cdot 4$ & $27 \cdot 0$ \\
\hline $35-49$ years & 33.7 & $31 \cdot 3$ \\
\hline $50-65$ years & 39.9 & 41.7 \\
\hline \multicolumn{3}{|l|}{ Education $(\%) \dagger$} \\
\hline Low & $26 \cdot 3$ & $29 \cdot 9$ \\
\hline Middle & $42 \cdot 2$ & $43 \cdot 3$ \\
\hline High & $31 \cdot 3$ & $26 \cdot 8$ \\
\hline \multicolumn{3}{|l|}{ BMI (\%) } \\
\hline Underweight $\left(<20 \mathrm{~kg} / \mathrm{m}^{2}\right)$ & $2 \cdot 2$ & $2 \cdot 8$ \\
\hline Normal weight $\left(20-25 \mathrm{~kg} / \mathrm{m}^{2}\right)$ & $41 \cdot 0$ & $46 \cdot 6$ \\
\hline Overweight $\left(25-30 \mathrm{~kg} / \mathrm{m}^{2}\right)$ & 43.5 & $30 \cdot 0$ \\
\hline Obese $\left(>30 \mathrm{~kg} / \mathrm{m}^{2}\right)$ & $15 \cdot 5$ & $20 \cdot 6$ \\
\hline
\end{tabular}

†Based on the official Dutch education classification (http://www.cbs.nl/NR/ rdonlyres/7C94DE33-621C-4355-928A-8B90F9F5D777/0/2006soiniveauind eling201213.pdf) which is similar to the classification by Kocken et al. ${ }^{(48)}$. This classification of items was not made explicit to participants. We obtained portion sizes and caloric values from the website of the Dutch Nutrition Center (http://www. voedingscentrum.nl/nl/schijf-van-vijf/eet-gevarieerd/ hoeveel-calorieen-zitten-erin.aspx). The proportion of low-calorie choices was calculated by dividing the total lowcalorie choices by the total low- and high-calorie choices combined. This was also done for individual products with both low-calorie and high-calorie versions (e.g. soft drinks). An overview of FFQ items can be found in Tables 2 and 3.

Main meal consumption patterns were identified by asking participants how often they normally consume breakfast, lunch and dinner: less than once per month/ never, 1-3 times per month, 1-3 times per week, 4-6 times per week, daily and several times per day. Main meal consumption patterns were included because they are known to be associated with snack consumption ${ }^{(9)}$. Because the majority of participants did consume main meals daily (ranging from $78.1 \%$ for breakfast to $92.4 \%$ for dinner), the items were dichotomized (e.g. daily breakfast: yes/no).

\section{Data analysis}

Data were analysed in three subsequent steps. First, because both existing measures and self-constructed measures were used, we performed confirmatory factor analysis and assessed internal consistency for the measures for the motivation, the opportunity and the ability to

Table 2 Mean weekly consumption of snack food FFQ items among a representative sample $(n 1318)$ of the Dutch population

\begin{tabular}{|c|c|c|c|c|}
\hline Category & Snack food items FFQ & $\% \dagger$ & Mean & SD \\
\hline \multirow[t]{10}{*}{ Sweet snacks } & Low-calorie & & & \\
\hline & (Fruit) biscuit & $24 \cdot 0$ & 0.97 & 1.84 \\
\hline & $\begin{array}{l}\text { Small candy barl } \\
\text { chocolate }\end{array}$ & $25 \cdot 9$ & 1.01 & 1.73 \\
\hline & Gingerbread & $29 \cdot 6$ & 1.25 & 2.07 \\
\hline & Water ice & 8.8 & 0.42 & 1.21 \\
\hline & High-calorie & & & \\
\hline & Cake and cookies & 39.9 & 1.69 & $2 \cdot 51$ \\
\hline & $\begin{array}{l}\text { Regular candy bar/ } \\
\text { chocolate }\end{array}$ & $15 \cdot 9$ & 0.63 & 1.27 \\
\hline & $\mathrm{Pie}$ & 7.6 & 0.43 & 0.73 \\
\hline & Ice cream & $9 \cdot 3$ & 0.46 & 1.14 \\
\hline \multirow[t]{8}{*}{ Savoury snacks } & Low-calorie & & & \\
\hline & Soup & $23 \cdot 1$ & 0.90 & 1.61 \\
\hline & Crackers $\ddagger$ & $26 \cdot 9$ & 1.17 & $2 \cdot 20$ \\
\hline & High-calorie & & & \\
\hline & Warm snacks§ & $12 \cdot 7$ & 0.50 & 0.87 \\
\hline & Nuts & $29 \cdot 1$ & 1.14 & 1.88 \\
\hline & Crisps & $35 \cdot 3$ & 1.14 & 1.49 \\
\hline & Sandwich & $40 \cdot 6$ & $2 \cdot 86$ & 4.33 \\
\hline \multirow{2}{*}{$\begin{array}{l}\text { Fruits and } \\
\text { vegetables }\end{array}$} & Fruits & $82 \cdot 2$ & $5 \cdot 73$ & 4.58 \\
\hline & Vegetables & 58.9 & 3.62 & 3.93 \\
\hline
\end{tabular}

†Percentage of participants who consumed the snack food $\geq 1$ time per week.

$\ddagger$ These included regular crackers, rice crackers and rusks.

$\S$ These included typical Dutch snacks ('kroket' and 'frikadel') and pizza slices. 
Table 3 Mean weekly consumption of beverage FFQ items among a representative sample $(n 1318)$ of the Dutch population

\begin{tabular}{|c|c|c|c|c|}
\hline Category & Beverage items FFQ & $\% \dagger$ & Mean & SD \\
\hline \multirow[t]{6}{*}{ Hot beverages } & Low-calorie & & & \\
\hline & Coffee & $76 \cdot 1$ & 8.62 & $6 \cdot 01$ \\
\hline & Tea & 71.9 & 6.79 & $5 \cdot 81$ \\
\hline & High-calorie & & & \\
\hline & Cappuccino & $28 \cdot 3$ & 1.92 & 3.84 \\
\hline & Chocolate milk & $10 \cdot 2$ & 0.56 & 1.65 \\
\hline \multirow[t]{9}{*}{ Cold beverages } & Low-calorie & & & \\
\hline & (Flavoured) water & $68 \cdot 4$ & $6 \cdot 82$ & $6 \cdot 00$ \\
\hline & Fruit juice light & $19 \cdot 8$ & 0.95 & $2 \cdot 28$ \\
\hline & Soft drink light & $32 \cdot 1$ & $2 \cdot 20$ & 4.03 \\
\hline & High-calorie & & & \\
\hline & Fruit juice regular & 33.6 & 1.65 & $2 \cdot 84$ \\
\hline & Soft drink regular & 28.5 & 1.59 & $3 \cdot 22$ \\
\hline & Milk & $46 \cdot 7$ & 3.05 & 4.04 \\
\hline & Yoghurt drink & $21 \cdot 3$ & 1.08 & $2 \cdot 38$ \\
\hline \multirow[t]{6}{*}{ Alcoholic beverages } & Low-calorie & & & \\
\hline & Malt/light beer & $4 \cdot 3$ & 0.21 & 1.07 \\
\hline & High-calorie & & & \\
\hline & Regular beer & $22 \cdot 3$ & 0.92 & $2 \cdot 10$ \\
\hline & Wine & $25 \cdot 3$ & $1 \cdot 11$ & $2 \cdot 29$ \\
\hline & Liquor & $8 \cdot 1$ & 0.39 & 1.42 \\
\hline
\end{tabular}

†Percentage of participants who consumed the beverage $\geq 1$ time per week.

choose low-calorie over high-calorie snacks using the $\mathrm{R}$ package lavaan (version $0 \cdot 5-17)^{(49)}$. The confirmatory factor analysis assessed the goodness-of-fit on four indices (cut-off values were adapted from Hair et al. ${ }^{(50)}$ ): (i) the comparative fit index (CFI; good if >0.95); (ii) the Tucker-Lewis index (TLI; good if $>0.95$ ); (iii) the rootmean-square error of approximation (RMSEA; good if $<0 \cdot 07$ ); and (iv) the standardized root-mean-square residual (SRMR; good if <0.08). First, measurement fit was investigated for the one-factor models. Then the overall multi-factor measurement model was evaluated, to ensure that the items loaded on their corresponding factor and not on one of the other factors. Internal consistency was evaluated based on $\omega^{2}$ and average variance extracted (AVE). Internal consistency was regarded as satisfactory when $\omega^{2}>0.7^{(51)}$ and AVE $>0.5^{(52)}$. Discriminant validity was regarded satisfactory when the AVE exceeded shared variance with other factors ${ }^{(52)}$.

Second, for snack foods and beverages separately we estimated the relationship between the MOA factors and demographic variables, on the one hand, and the proportion of low-calorie choices, on the other, by conducting a linear regression analysis. The relationship was estimated for both the aggregated proportions of low-calorie choices and proportions of low-calorie choices for individual products with a low-calorie and high-calorie version (e.g. soft drinks). To be able to perform linear regression analysis on the proportions of low-calorie choices, a function of proportions was used: the log odds $^{(53)}$. Log odds scores were obtained by taking the logit of the probability of choosing a low-calorie snack (the number of low-calorie snack choices divided by the number of high-calorie snack choices). Because proportions of 0 and 1 have no log odds, these scores were imputed $^{(54)}$, meaning that proportions of 0 and 1 received the log odds of the lowest and highest proportions (which were $>0$ and $<1$ ) in the data set, respectively.

Third, for snack foods and beverages separately we examined if and how many dominant profiles could be identified based on the motivation, the opportunity and the ability to choose low-calorie over high-calorie snacks. Initially, hierarchical cluster solutions of two to ten profiles were generated using the statistical software package IBM SPSS Statistics 19.0. The hierarchical centroids that were obtained were then used as starting points for $k$-means clustering. Because the agglomeration schedule was inconclusive in assessing the best cluster solution, the final profile number was determined by using $\mathrm{R}$ package NbClust (version $2 \cdot 0)^{(55)}$, which provides several indices for identifying the relevant number of clusters. We subsequently performed ANOVA to identify differences in daily meal consumption and snacking behaviour between the dominant profiles. Within each ANOVA, we ran post hoc comparisons using Tukey's honest significant difference procedure to control the family-wise error rate.

\section{Results}

\section{Psychometric properties of motivation, opportunity and ability measures (Step 1)}

Tables 4 and 5 show that the psychometric properties for the MOA measures were close to identical for snack foods and beverages. Internal consistency was satisfactory both for the snack food and beverage Motivation measures, while discriminant validity was adequate. Within the three Opportunity measures, the AVE and thus the discriminant validity suffered from three oppositely phrased items (one in each of three measures). Removal of two oppositely phrased items for physical Opportunity ('I think that lowcalorie snacks, compared to high-calorie snacks, are easy enough to find') and financial Opportunity ('I think that lowcalorie snacks, compared to high-calorie snacks, are on sale often enough') resulted in an AVE $>0.5$, thereby reaching satisfactory internal consistency and adequate discriminant validity. Because media Opportunity consisted of only two items, both were kept, even though internal consistency and discriminant validity were not completely achieved. For Ability (knowledge) internal consistency was borderline satisfactory (AVE values of 0.487 and 0.456), while discriminant validity was adequate. Because removal of the item with the lowest $R^{2}$ did not result in a better overall $\omega^{2}$ value, we proceeded with all four knowledge items.

Table 4 also shows the fit measures for the one-factor models and overall measurement models of the MOA measures for snack foods, with and without the removal of items. The CFI, TLI, RMSEA and SRMR all indicated a good fit for the one-factor models. For the overall measurement model the CFI and TLI were low (0.935 and 0.922), and 
Table 4 Internal consistency and fit measures for the one-factor models and the overall measurement model (snack foods)

\begin{tabular}{|c|c|c|c|c|c|c|c|c|c|c|c|}
\hline & \multirow[b]{2}{*}{$\omega^{2}$} & \multirow[b]{2}{*}{ AVE } & \multirow[b]{2}{*}{$x^{2}$} & \multirow[b]{2}{*}{$P$ value } & \multirow[b]{2}{*}{$d f$} & \multirow[b]{2}{*}{$\mathrm{CFI}$} & \multirow[b]{2}{*}{ TLI } & \multicolumn{3}{|c|}{ RMSEA } & \multirow[b]{2}{*}{ SRMR } \\
\hline & & & & & & & & Value & $90 \%$ LB & $90 \%$ UB & \\
\hline \multicolumn{12}{|l|}{ One-factor modelst } \\
\hline Attitude (cognitive) & 0.902 & 0.700 & 3.72 & 0.16 & 2 & 0.999 & 0.997 & 0.026 & 0.000 & 0.050 & 0.007 \\
\hline Attitude (affective) & 0.902 & 0.687 & 0.86 & 0.65 & 2 & 1.000 & 1.002 & 0.000 & 0.000 & 0.034 & 0.003 \\
\hline Personal norms & 0.917 & 0.786 & - & - & - & - & - & - & - & - & - \\
\hline Opportunity (physical) & $\begin{array}{l}0.794 \\
0.815 \S\end{array}$ & $\begin{array}{l}0.497 \\
0.596 \S\end{array}$ & $2 \cdot 14$ & 0.34 & 2 & 1.000 & 1.000 & 0.007 & 0.000 & 0.048 & 0.008 \\
\hline Opportunity (media) & 0.543 & 0.410 & - & - & - & - & - & - & - & - & - \\
\hline Opportunity (financial) & $\begin{array}{l}0.837 \\
0.866 \S\end{array}$ & $\begin{array}{l}0.568 \\
0.684 \S\end{array}$ & $15 \cdot 06$ & 0.001 & 2 & 0.990 & 0.969 & 0.070 & 0.043 & 0.101 & 0.018 \\
\hline $\begin{array}{l}\text { Ability (knowledge) } \\
\text { Overall model with all itemst }\end{array}$ & 0.790 & 0.487 & $\begin{array}{r}4.91 \\
1229.24\end{array}$ & $\begin{array}{l}0.09 \\
0.00\end{array}$ & 2 & $\begin{array}{l}0.997 \\
0.935\end{array}$ & $\begin{array}{l}0.991 \\
0.922\end{array}$ & $\begin{array}{l}0.033 \\
0.05\end{array}$ & $\begin{array}{l}0.004 \\
0.047\end{array}$ & $\begin{array}{l}0.061 \\
0.052\end{array}$ & $\begin{array}{l}0.012 \\
0.055\end{array}$ \\
\hline $\begin{array}{l}\text { Overall model without } \\
\text { oppositely phrased items } \ddagger\end{array}$ & & & $\begin{array}{r}1229 \cdot 24 \\
734.88\end{array}$ & 0.00 & $\begin{array}{l}290 \\
241\end{array}$ & 0.964 & 0.956 & 0.039 & 0.037 & 0.042 & $\begin{array}{l}0.035 \\
0.039\end{array}$ \\
\hline
\end{tabular}

AVE, average variance extracted; CFI, comparative fit index; TLI, Tucker-Lewis index; RMSEA, root-mean-square error of approximation; LB, lower bound; UB, upper bound; SRMR, standardized root-mean-square residual.

†For social norm and Ability (skills), no fit measures are available as they consist of one item.

¥Social norm and Ability (skills) are in the overall measurement model. Error variance of these measures was set to 0.4 , which is in the same range as other error variances.

§Value after removing the oppositely phrased item.

Table 5 Internal consistency and fit measures for the one-factor models and the overall measurement model (beverages)

\begin{tabular}{|c|c|c|c|c|c|c|c|c|c|c|c|}
\hline & \multirow[b]{2}{*}{$\omega^{2}$} & \multirow[b]{2}{*}{ AVE } & \multirow[b]{2}{*}{$x^{2}$} & \multirow[b]{2}{*}{$P$ value } & \multirow[b]{2}{*}{ df } & \multirow[b]{2}{*}{$\mathrm{CFI}$} & \multirow[b]{2}{*}{ TLI } & \multicolumn{3}{|c|}{ RMSEA } & \multirow[b]{2}{*}{ SRMR } \\
\hline & & & & & & & & Value & $90 \%$ LB & $90 \%$ UB & \\
\hline \multicolumn{12}{|l|}{ One-factor modelst } \\
\hline Attitude (cognitive) & 0.925 & 0.758 & 4.942 & 0.09 & 2 & 0.999 & 0.996 & 0.033 & 0.013 & 0.054 & 0.008 \\
\hline Attitude (affective) & 0.902 & 0.683 & $1 \cdot 18$ & 0.55 & 2 & 1.000 & 1.001 & 0.000 & 0.000 & 0.040 & 0.003 \\
\hline Personal norms & 0.926 & 0.805 & - & - & - & - & - & - & - & - & - \\
\hline Opportunity (physical) & $\begin{array}{l}0.807 \\
0.823 \S\end{array}$ & $\begin{array}{l}0.515 \\
0.612 \S\end{array}$ & 1.61 & 0.45 & 2 & 1.000 & 1.001 & 0.000 & 0.000 & 0.039 & 0.007 \\
\hline Opportunity (media) & 0.543 & 0.410 & - & - & - & - & - & - & - & - & - \\
\hline Opportunity (financial) & $\begin{array}{l}0.822 \\
0.846 \S\end{array}$ & $\begin{array}{l}0.540 \\
0.648 \S\end{array}$ & $16 \cdot 47$ & 0.00 & 2 & 0.988 & 0.964 & 0.074 & 0.050 & $0 \cdot 100$ & 0.021 \\
\hline Ability (knowledge) & 0.769 & 0.456 & $17 \cdot 43$ & 0.00 & 2 & 0.982 & 0.947 & 0.077 & 0.054 & 0.101 & 0.023 \\
\hline Overall model with all itemsł & & & $1067 \cdot 87$ & 0.00 & 290 & 0.951 & 0.941 & 0.045 & 0.043 & 0.048 & 0.050 \\
\hline $\begin{array}{l}\text { Overall model without } \\
\text { oppositely phrased items } \neq\end{array}$ & & & $647 \cdot 76$ & 0.00 & 241 & 0.973 & 0.967 & 0.036 & 0.033 & 0.039 & 0.038 \\
\hline
\end{tabular}

AVE, average variance extracted; CFI, comparative fit index; TLI, Tucker-Lewis index; RMSEA, root-mean-square error of approximation; LB, lower bound; UB, upper bound; SRMR, standardized root-mean-square residual.

†For social norm and Ability (skills), no fit measures are available as they consist of one item.

¥Social norm and Ability (skills) are in the overall measurement model. Error variance of these measures was set to 0.4 , which is in the same range as other error variances.

$\S$ Value after removing the oppositely phrased item.

therefore we tested the measurement model without the two oppositely phrased physical and financial Opportunity items. With the omission of these items, the CFI and TLI changed to acceptable values of 0.964 and 0.956 , respectively.

For the MOA measures for beverages (Table 5), CFI and SRMR indicated good fit for the one-factor models. The TLI for Ability (knowledge) was slightly lower than the cut-off value (0.947). Similarly, the RMSEA for Opportunity (financial) and Ability (knowledge) were slightly higher than the cut-off $(0.074$ and $0 \cdot 077$, respectively). Because these measures were only slightly lower than the cut-off and scored a good fit on the other indices, we evaluated the fit of the one-factor models as acceptable. For the overall measurement model, the TLI was too low (0.941).
Therefore we again tested the measurement model without the two oppositely phrased physical and financial Opportunity items and found that TLI changed to an acceptable value of 0.967 .

Because of the considerable improvements in both internal consistency and overall measurement model fit, we decided to conduct further analysis without the two oppositely phrased physical and financial Opportunity items.

\section{Relationship between motivation, opportunity and ability factors and the log odds of choosing low-calorie snack foods (Step 2)}

Table 6 shows the outcomes of the linear regression analysis on the log odds of choosing low-calorie snack foods. 
The model for snack foods, in which we consecutively included the MOA factors for snack foods $\left(R^{2}=0.132\right.$, adjusted $\left.R^{2}=0 \cdot 126\right)$ and demographic variables $\left(\Delta R^{2}=\right.$ $0 \cdot 044$, adjusted $\Delta R^{2}=0 \cdot 042$ ), accounted for $17 \cdot 6 \%$ (adjusted $16.8 \%$ ) of the variance in the log odds of choosing lowcalorie snack foods.

Within MOA, significant positive effects on the log odds of choosing low-calorie snack foods were identified for affective attitude, personal norm, financial opportunity and skills in understanding calorie information on packages. Eating breakfast daily also had a positive effect. Women were more likely to choose low-calorie snack foods, while younger people and people with a lower education were less likely to choose low-calorie snack foods. The $\beta$ values in Table 6 indicate the change in log odds. These changes can be translated back into odds ratios (proportion low-calorie divided by proportion high-calorie). The personal norm coefficient of $0 \cdot 162$, for instance, corresponds to an $18 \%$ increase of the odds of choosing low-calorie snack foods.

\section{Relationship between motivation, opportunity and ability factors and the log odds of choosing low-calorie beverages (Step 2)}

Table 6 furthermore shows the outcomes of the linear regression analysis on the $\log$ odds of choosing

Table 6 Linear regression analysis on the log odds of choosing low-calorie snacks

\begin{tabular}{|c|c|c|c|c|}
\hline & \multicolumn{2}{|c|}{ Snack foods $†$} & \multicolumn{2}{|c|}{ Beveragesł } \\
\hline & $\beta$ & $P$ & $\beta$ & $P$ \\
\hline \multicolumn{5}{|l|}{ MOA factors } \\
\hline \multicolumn{5}{|l|}{ Motivation } \\
\hline \multicolumn{5}{|l|}{ Attitude } \\
\hline Cognitive & 0.009 & 0.796 & 0.056 & 0.196 \\
\hline Affective & $0.147^{\star \star \star}$ & 0.000 & $0.086^{*}$ & 0.034 \\
\hline Personal norm & $0 \cdot 162^{\star \star \star}$ & 0.000 & $0 \cdot 164^{\star \star \star}$ & 0.000 \\
\hline Social norm & -0.029 & 0.326 & $-0.073^{\star}$ & 0.017 \\
\hline \multicolumn{5}{|l|}{ Opportunity } \\
\hline Physical & -0.054 & 0.138 & 0.046 & 0.221 \\
\hline Media & -0.036 & 0.223 & -0.021 & 0.501 \\
\hline Financial & $0.078^{*}$ & 0.020 & 0.021 & 0.550 \\
\hline \multicolumn{5}{|l|}{ Ability } \\
\hline Knowledge & -0.005 & 0.836 & -0.026 & 0.330 \\
\hline Skills & $0 \cdot 102^{\star \star \star}$ & 0.000 & 0.001 & 0.964 \\
\hline \multicolumn{5}{|l|}{ Demographic variables } \\
\hline Gender (male) & $-0 \cdot 115^{\star \star \star}$ & 0.000 & $-0.106^{\star \star \star}$ & 0.000 \\
\hline BMI $\left(\mathrm{kg} / \mathrm{m}^{2}\right)$ & 0.004 & 0.885 & 0.012 & 0.669 \\
\hline \multicolumn{5}{|l|}{ Age } \\
\hline $\begin{array}{l}18-34 \text { years } v .50-65 \\
\text { years }\end{array}$ & $-0 \cdot 106^{\star \star \star}$ & 0.000 & -0.044 & 0.141 \\
\hline $\begin{array}{l}\text { 35-49 years } v .50-65 \\
\text { years }\end{array}$ & $-0 \cdot 130^{\star \star \star}$ & 0.000 & -0.042 & $0 \cdot 151$ \\
\hline \multicolumn{5}{|l|}{ Education } \\
\hline Low $v$. high & $-0 \cdot 120^{\star \star \star}$ & 0.000 & -0.046 & 0.155 \\
\hline Middle $v$. high & $-0.098^{\star *}$ & 0.001 & -0.026 & 0.409 \\
\hline Daily breakfast (yes) & $0.058^{*}$ & 0.050 & 0.049 & 0.103 \\
\hline Daily lunch (yes) & 0.013 & 0.694 & 0.049 & 0.132 \\
\hline Daily dinner (yes) & 0.026 & 0.379 & 0.027 & 0.379 \\
\hline
\end{tabular}

MOA, motivation-opportunity-ability.

${ }^{*} P<0.05,{ }^{* *} P<0.01,{ }^{* * *} P<0.001$

$\dagger R^{2}=0.176$ (adjusted $R^{2}=0.164$ ).

$\ddagger R^{2}=0.126$ (adjusted $R^{2}=0 \cdot 114$ ). low-calorie beverages. The total model for beverages, in which we consecutively included the MOA factors for beverages $\left(R^{2}=0 \cdot 101\right.$, adjusted $\left.R^{2}=0.095\right)$ and demographic variables $\left(\Delta R^{2}=0 \cdot 025\right.$, adjusted $\left.\Delta R^{2}=0 \cdot 019\right)$, accounted for $12.6 \%$ (adjusted $11.4 \%$ ) of the variance in the log odds of choosing low-calorie beverages.

With regard to the MOA factors, positive effects on the log odds of choosing low-calorie beverages were identified for affective attitude and personal norm, while social norm had a negative effect. Again, women were more likely to choose low-calorie beverages.

Linear regression analysis was also conducted on the log odds of choosing the low-calorie version of beverages that have both a high- and a low-calorie version. This included light fruit juice $v$. fruit juice regular and light soft drink $v$. regular soft drink. To ensure that only respondents who choose these beverages regularly were included in the regression, a criterion of $>3$ times per week was used. For the log odds of choosing light fruit juice, $R^{2}$ values for MOA $\left(R^{2}=0 \cdot 104\right)$ and demographics $\left(\Delta R^{2}=0.028\right)$ were similar to the aggregated low-calorie beverage log odds. For soft drinks, the total model accounted for $27.9 \%$ of the variance in the log odds of choosing light soft drinks (MOA $R^{2}=0 \cdot 240$, demographics $\Delta R^{2}=0 \cdot 039$ ). Due to a relatively small number of respondents who drink soda regularly, the adjusted $R^{2}$ amounted to 0.217 and the adjusted $\Delta R^{2}$ to $0 \cdot 021$.

\section{Profiles based on motivation, opportunity and ability factors (Step 3)}

Rothschild's MOA framework theoretically differentiates between eight possible profile types based on whether barriers within the motivation, the opportunity and the ability to choose low-calorie over high-calorie snacks were present. Table 7 gives the sizes of these eight MOA profile types, which were identified by means of a split on the midpoint of the scales for the averaged motivation, opportunity and ability scores $(\leq 4=$ no, $>4=$ yes $)$, for both snack foods and beverages.

The distribution across the profiles was similar for snack foods and beverages. The majority was motivated to a degree (70\% and $73 \%$ ) and about half of the participants

Table 7 Percentage of participants with or without barriers regarding motivation, opportunity and ability to choose low-calorie snacks, based on a score split $(n 1318)$

\begin{tabular}{|c|c|c|c|c|c|c|c|c|}
\hline \multirow{3}{*}{$\begin{array}{l}\text { Motivation } \\
\text { Opportunity }\end{array}$} & \multicolumn{4}{|c|}{ No barrier (\%) } & \multicolumn{4}{|c|}{ Barrier (\%) } \\
\hline & \multicolumn{2}{|c|}{ No barrier } & \multicolumn{2}{|c|}{ Barrier } & \multicolumn{2}{|c|}{ No barrier } & \multicolumn{2}{|c|}{ Barrier } \\
\hline & SF & $B$ & SF & $B$ & SF & $B$ & SF & B \\
\hline \multicolumn{9}{|l|}{ Ability } \\
\hline No barrier & 19 & 27 & 21 & 14 & 7 & 7 & 5 & 3 \\
\hline Barrier & 10 & 14 & 20 & 18 & 6 & 7 & 12 & 10 \\
\hline
\end{tabular}

SF, snack foods; B, beverages. 
Table 8 Profiles based on barriers regarding the motivation, the opportunity and the ability to choose low-calorie over high-calorie snacks among a representative sample $(n$ 1318) of the Dutch population

\begin{tabular}{|c|c|c|c|c|c|c|c|c|c|c|c|c|c|c|c|c|c|c|}
\hline & \multicolumn{4}{|c|}{ Overall } & \multicolumn{4}{|c|}{ No-barrier profile } & \multicolumn{4}{|c|}{ Lack-of-opportunity profile } & \multicolumn{4}{|c|}{ Lack-of-motivation profile } & \multirow{3}{*}{$\begin{array}{c}\begin{array}{c}\text { Snack } \\
\text { foods }\end{array} \\
\text { F† }\end{array}$} & \multirow{3}{*}{$\frac{\text { Beverages }}{\mathrm{F} \dagger}$} \\
\hline & \multicolumn{2}{|c|}{$\begin{array}{l}\text { Snack } \\
\text { foods }\end{array}$} & \multicolumn{2}{|c|}{ Beverages } & \multicolumn{2}{|c|}{$\begin{array}{l}\text { Snack foods } \\
\qquad(n \text { 352) }\end{array}$} & \multicolumn{2}{|c|}{$\begin{array}{c}\text { Beverages } \\
(n \text { 406) }\end{array}$} & \multicolumn{2}{|c|}{$\begin{array}{l}\text { Snack foods } \\
\text { (n 501) }\end{array}$} & \multicolumn{2}{|c|}{$\begin{array}{l}\text { Beverages } \\
\quad(n \text { 492) }\end{array}$} & \multicolumn{2}{|c|}{$\begin{array}{l}\text { Snack foods } \\
\text { (n 465) }\end{array}$} & \multicolumn{2}{|c|}{$\begin{array}{c}\text { Beverages } \\
(n 420)\end{array}$} & & \\
\hline & Mean & SD & Mean & SD & Mean & SD & Mean & SD & Mean & SD & Mean & SD & Mean & SD & Mean & SD & & \\
\hline \multicolumn{19}{|l|}{ Barriers } \\
\hline \multicolumn{19}{|l|}{ Motivation } \\
\hline \multicolumn{19}{|l|}{ Attitude } \\
\hline Cognitive & $5 \cdot 40$ & 1.28 & 5.52 & 1.32 & $6 \cdot 24^{a}$ & 0.83 & $6 \cdot 40^{x}$ & 0.68 & $5 \cdot 81^{b}$ & 1.01 & $5 \cdot 91^{y}$ & 0.93 & $4 \cdot 31^{\mathrm{c}}$ & 1.05 & $4 \cdot 20^{z}$ & $1 \cdot 15$ & $461 \cdot 68^{\star \star \star}$ & $625 \cdot 50^{\star \star \star}$ \\
\hline Affective & 4.53 & 1.29 & 4.88 & $1 \cdot 30$ & $5 \cdot 19^{\mathrm{a}}$ & $1 \cdot 17$ & $5 \cdot 65^{x}$ & 0.93 & $4 \cdot 84^{b}$ & $1 \cdot 16$ & $5 \cdot 18^{y}$ & 1.06 & $3.69^{c}$ & 1.03 & $3.77^{z}$ & $1 \cdot 10$ & $212 \cdot 18^{\star \star \star}$ & $372 \cdot 16^{\star \star \star}$ \\
\hline Personal norm & 4.82 & 1.52 & 4.87 & 1.64 & $5 \cdot 65^{\mathrm{a}}$ & 1.01 & $5 \cdot 82^{x}$ & 1.03 & $5 \cdot 63^{\mathrm{a}}$ & 0.87 & $5 \cdot 63^{y}$ & 0.97 & $3 \cdot 31^{b}$ & $1 \cdot 21$ & $3.06^{z}$ & 1.22 & $752 \cdot 01^{\star * \star}$ & $877 \cdot 21^{\star \star \star}$ \\
\hline Social norm & 3.74 & 1.72 & 3.64 & $1 \cdot 74$ & $3 \cdot 40^{\mathrm{a}}$ & 1.79 & $3.72^{x}$ & 1.87 & $4.85^{b}$ & 1.36 & $4.47^{y}$ & 1.46 & $2 \cdot 79^{c}$ & $1 \cdot 30$ & $2 \cdot 59^{z}$ & 1.30 & $251 \cdot 90^{\text {***}}$ & $165 \cdot 99^{\text {***}}$ \\
\hline \multicolumn{19}{|l|}{ Opportunity $\ddagger$} \\
\hline Physical & $4 \cdot 30$ & 1.19 & 4.69 & $1 \cdot 21$ & $5 \cdot 29^{a}$ & 1.01 & $5 \cdot 65^{x}$ & 0.89 & $3.54^{b}$ & 0.97 & $3.90^{y}$ & 0.99 & $4 \cdot 37^{c}$ & 0.94 & $4 \cdot 67^{z}$ & 1.02 & $341 \cdot 34^{\star \star \star}$ & $360 \cdot 32^{\star \star \star}$ \\
\hline Media & 4.06 & 1.11 & 4.33 & $1 \cdot 14$ & $4.65^{\mathrm{a}}$ & $1 \cdot 15$ & $4.94^{x}$ & 1.15 & $3.56^{b}$ & 1.02 & $3 \cdot 74^{y}$ & 1.00 & $4 \cdot 15^{c}$ & 0.90 & $4.43^{z}$ & 0.94 & $122 \cdot 28^{\text {***}}$ & $153 \cdot 74^{\star \star \star *}$ \\
\hline Financial & 3.66 & $1 \cdot 26$ & 4.03 & $1 \cdot 28$ & $4.45^{\mathrm{a}}$ & 1.35 & $4.95^{x}$ & $1 \cdot 15$ & $2.95^{b}$ & 0.96 & $3 \cdot 22^{y}$ & 1.00 & $3.82^{c}$ & 1.04 & $4 \cdot 10^{z}$ & 1.06 & $198.05^{\star \star *}$ & $291 \cdot 14^{\star \star \star *}$ \\
\hline \multicolumn{19}{|l|}{ Ability } \\
\hline Knowledge & 3.89 & 1.19 & 3.92 & 1.17 & $4.09^{a}$ & 1.31 & $4 \cdot 14^{x}$ & 1.25 & $3.90^{\mathrm{a}}$ & 1.21 & $3.96^{x}$ & 1.20 & $3.71^{b}$ & 1.03 & $3.66^{y}$ & 1.00 & $11.54^{\star \star \star}$ & $18 \cdot 11^{\star \star \star}$ \\
\hline Skillsł & 4.64 & 1.51 & $4 \cdot 70$ & 1.53 & $5 \cdot 81^{a}$ & $1 \cdot 12$ & $5 \cdot 77^{x}$ & $1 \cdot 11$ & $4 \cdot 10^{\mathrm{b}}$ & 1.45 & $3.97^{y}$ & 1.48 & $4 \cdot 35^{c}$ & 1.36 & $4.53^{z}$ & 1.36 & $187 \cdot 63^{\star \star \star}$ & $207 \cdot 32^{\star \star \star}$ \\
\hline
\end{tabular}

a,b,c,x,y,z One-way ANOVA and $\chi^{2}$ tests were carried out to identify differences between profiles; ${ }^{a, b, c}$ are used to indicate differences between snack food profiles, $x, y, z$ for beverage profiles. Mean values within a row with unlike superscript letters were significantly different, based on Tukey's post hoc test. ${ }^{\star} P<0.05,{ }^{\star \star} P<0.01,{ }^{\star \star \star} P<0.001$.

$\mathrm{tdf}_{1}, \mathrm{df}_{2}=2,1316$

¥Opportunity and skill scores were reversed because the items were reverse-scored.

perceived to have sufficient ability ( $51 \%$ and $50 \%$ ) to select low-calorie snacks. The profiles did however differ regarding opportunity; for snacks foods $41 \%$ of participants perceived the opportunity to be sufficient, while this was $54 \%$ for beverages. Correspondingly, the group with no barriers was larger for beverages (27\%) than for snack foods (19\%).

\section{Identification of dominant motivation-opportunity-ability profiles}

After considering the Calinsky-Harabasz, silhouette and Gap indices and investigating the patterns of significant and meaningful differences in terms of motivation, ability and opportunity, we concluded that a three-cluster solution provided the most parsimonious grouping. Table 8 shows the scores on the MOA factors for snack foods and beverages for each of the profiles. The three snack food profiles and the three beverage profiles show very similar patterns. Therefore they will be described jointly in the next paragraphs.

The 'no-barrier profile' is characterized by a very high motivation to choose low-calorie over high-calorie snacks, without social pressure to do so. People with this profile perceive themselves as sufficiently able to make low-calorie over high-calorie choices and they also feel that the opportunity to make these choices is present. Overall, people with this profile report having no barriers to choose low-calorie over high-calorie snacks in real life. For both snack foods and beverages, the no-barrier profile has the highest overall proportion of low-calorie choices (69\% for snack foods and $76 \%$ for beverages).
The 'lack-of-opportunity profile' is also characterized by a high motivation to choose low-calorie over high-calorie snacks, coupled with some social pressure to do so. In contrast to the no-barrier profile, people with this profile perceive that there is insufficient opportunity to choose low-calorie snacks, particularly regarding the financial costs of obtaining low-calorie products. Even though they are motivated, people with the lack-of-opportunity profile are unsure about having sufficient knowledge and skills to be able to choose low-calorie over high-calorie snacks. The overall proportion of low-calorie choices is lower than in the no-barrier profile, both for snack foods (62\%) and beverages $(70 \%)$.

The 'lack-of-motivation profile' distinguishes itself from the no-barrier and lack-of-opportunity profile by a low motivation to choose low-calorie over high-calorie snacks. Although people with this profile think the opportunity to choose low-calorie over high-calorie snacks is less than those with the no-barrier profile, they do feel that it is more sufficient than people with the lack-of-opportunity profile. In addition to a low motivation score, the perceived ability to choose lowcalorie over high-calorie options of those with the lack-of-motivation profile is also below average. In terms of snacking behaviour, the lack-of-motivation profile is characterized by the lowest overall proportion of low-calorie choices, both for snack foods (53\%) and beverages (61\%).

Table 9 further describes the profiles in terms of snacking and eating behaviours, and also provides sociodemographic characteristics of each profile. For both snack foods and beverages, the composition of the 
Table 9 Profile characteristics regarding eating and snacking behaviour, and sociodemographic variables among a representative sample $(n 1318)$ of the Dutch population

\begin{tabular}{|c|c|c|c|c|c|c|c|c|c|c|c|c|c|c|c|c|c|c|}
\hline & \multirow{2}{*}{\multicolumn{2}{|c|}{$\begin{array}{c}\text { Overall } \\
\begin{array}{c}\text { Snack foods } \\
\text { and beverages }\end{array}\end{array}$}} & \multicolumn{4}{|c|}{ No-barrier profile } & \multicolumn{4}{|c|}{ Lack-of-opportunity profile } & \multicolumn{4}{|c|}{ Lack-of-motivation profile } & \multirow{2}{*}{\multicolumn{2}{|c|}{ Snack foods }} & \multirow{2}{*}{\multicolumn{2}{|c|}{ Beverages }} \\
\hline & & & \multicolumn{2}{|c|}{$\begin{array}{l}\text { Snack foods } \\
\quad(n 352)\end{array}$} & \multicolumn{2}{|c|}{$\begin{array}{l}\text { Beverages } \\
\quad(n \text { 406) }\end{array}$} & \multicolumn{2}{|c|}{$\begin{array}{l}\text { Snack foods } \\
\quad(n 501)\end{array}$} & \multicolumn{2}{|c|}{$\begin{array}{l}\text { Beverages } \\
(n \text { 492) }\end{array}$} & \multicolumn{2}{|c|}{$\begin{array}{l}\text { Snack foods } \\
\quad(n \text { 465) }\end{array}$} & \multicolumn{2}{|c|}{$\begin{array}{l}\text { Beverages } \\
\quad(n 420)\end{array}$} & & & & \\
\hline & $\underset{\%}{\operatorname{Mean} \text { or }}$ & SD & $\underset{\%}{\text { Mean or }}$ & SD & $\underset{\%}{\text { Mean or }}$ & SD & $\underset{\%}{\operatorname{Mean} \text { or }}$ & SD & $\underset{\%}{\text { Mean or }}$ & SD & $\underset{\%}{\text { Mean or }}$ & SD & $\underset{\%}{\text { Mean or }}$ & SD & $F$ or $x^{2}$ & $\begin{array}{ll}\mathrm{df}_{1}, \\
\mathrm{df}\end{array}$ & $F$ or $x^{2}$ & $\mathrm{df}_{1}, \mathrm{df}_{\mathrm{df}}$, or \\
\hline \multicolumn{19}{|l|}{ Eating behaviour } \\
\hline Daily breakfast (\%) & $79 \cdot 2$ & - & 88.4 & - & 85.5 & - & $80 \cdot 6$ & - & $79 \cdot 3$ & - & $70 \cdot 8$ & - & 73.1 & - & $38 \cdot 69^{\star \star *}$ & 2 & $19 \cdot 19^{\star \star \star}$ & 2 \\
\hline Daily lunch (\%) & 83.8 & - & 89.2 & - & 88.2 & - & 85.0 & - & 83.7 & - & 78.5 & - & 79.8 & - & $17 \cdot 81^{\star \star \star}$ & 2 & $10 \cdot 80^{\star \star}$ & 2 \\
\hline Daily dinner (\%) & $92 \cdot 6$ & - & 95.2 & - & $95 \cdot 1$ & - & $92 \cdot 2$ & - & $92 \cdot 3$ & - & 91.2 & - & 90.7 & - & $4.89^{\text {NS }}$ & 2 & $5.91^{\mathrm{NS}}$ & 2 \\
\hline \multicolumn{19}{|c|}{ Proportion of low-calorie choices per category } \\
\hline Sweet snacks & 0.48 & 0.30 & $0.54^{\mathrm{a}}$ & 0.32 & - & - & $0.48^{\mathrm{b}}$ & 0.30 & - & - & $0.43^{\mathrm{c}}$ & 0.27 & - & - & $13 \cdot 01^{* \star *}$ & 2,1316 & - & - \\
\hline Savoury snacks & 0.23 & 0.25 & $0.28^{\mathrm{a}}$ & 0.28 & - & - & $0.25^{\mathrm{a}}$ & 0.25 & - & - & $0.18^{\mathrm{b}}$ & 0.21 & - & - & $17 \cdot 23^{* \star \star}$ & 2,1316 & - & - \\
\hline Fruits and vegetables & 1.00 & 0.00 & 1.00 & 0.00 & - & - & 1.00 & 0.00 & - & - & 1.00 & 0.00 & - & - & & 2,1316 & - & _- \\
\hline Proportion of low-calorie snack foods & 0.61 & 0.22 & $0.69^{\mathrm{a}}$ & 0.21 & - & - & $0.62^{b}$ & 0.21 & - & - & $0.53^{\mathrm{C}}$ & 0.22 & - & - & $53 \cdot 44^{\star \star *}$ & 2,1316 & - & - \\
\hline Hot beverages & 0.85 & 0.23 & - & - & $0.88^{\mathrm{a}}$ & 0.18 & - & - & $0.85^{a, b}$ & 0.21 & - & - & $0.84^{\mathrm{b}}$ & 0.24 & - & - & $5 \cdot 76^{\star \star}$ & 2,1316 \\
\hline Cold beverages & 0.55 & 0.33 & - & - & $0.67^{\mathrm{a}}$ & 0.30 & - & - & $0.56^{\mathrm{b}}$ & 0.31 & - & - & $0.42^{\mathrm{c}}$ & 0.32 & - & - & $63 \cdot 32^{\star \star \star}$ & 2,1316 \\
\hline Alcoholic beverages & 0.05 & $0 \cdot 17$ & - & - & 0.04 & 0.15 & - & - & 0.06 & 0.19 & - & - & 0.05 & 0.15 & - & - & $2 \cdot 18^{\mathrm{NS}}$ & 2,1316 \\
\hline Proportion of low-calorie beverages & 0.69 & 0.20 & - & - & $0.76^{\mathrm{x}}$ & 0.17 & - & - & $0.70^{y}$ & 0.19 & - & - & $0.61^{z}$ & 0.22 & - & - & $64.81^{\star \star *}$ & 2,1316 \\
\hline \multicolumn{19}{|l|}{ Consumption frequency per week } \\
\hline Sweet snacks & 6.85 & 6.96 & $6 \cdot 25$ & $6 \cdot 21$ & - & - & 6.93 & 6.86 & - & - & $7 \cdot 21$ & 7.56 & - & - & $1.96^{\mathrm{NS}}$ & 2,1316 & - & - \\
\hline Savoury snacks & $8 \cdot 29$ & 7.67 & $6 \cdot 88^{\mathrm{a}}$ & $6 \cdot 70$ & - & - & $8.99^{b}$ & 8.06 & - & - & $8.58^{\mathrm{b}}$ & 7.81 & - & - & $8 \cdot 44^{\star \star \star}$ & 2, 1316 & - & - \\
\hline Fruits and vegetables & 9.35 & 7.35 & $11.02^{\mathrm{a}}$ & 7.65 & - & - & $9.84^{\mathrm{a}}$ & $7 \cdot 26$ & - & - & $7 \cdot 56^{\mathrm{b}}$ & 6.84 & - & - & $24 \cdot 74^{\star \star \star}$ & 2, 1316 & - & - \\
\hline Total snack foods per week & 24.48 & $15 \cdot 66$ & $24 \cdot 15$ & 14.39 & - & - & $25 \cdot 76$ & $16 \cdot 10$ & - & - & 23.36 & $16 \cdot 05$ & - & - & $2.95^{\mathrm{NS}}$ & 2,1316 & - & - \\
\hline Hot beverages & 17.89 & 8.87 & - & - & $19 \cdot 13^{x}$ & 8.62 & - & - & $18 \cdot 04^{x}$ & 8.93 & - & - & $16 \cdot 49^{y}$ & 8.92 & - & - & $9 \cdot 43^{\star \star \star}$ & 2,1316 \\
\hline Cold beverages & 17.34 & $11 \cdot 18$ & - & - & $17 \cdot 49^{x, y}$ & 9.90 & - & - & $18 \cdot 22^{x}$ & 11.95 & - & - & $16 \cdot 15^{y}$ & 11.41 & - & - & $3.97^{\star}$ & 2,1316 \\
\hline Alcoholic beverages & 2.63 & 4.23 & - & - & $2.01^{x}$ & 3.01 & - & - & $2 \cdot 53^{x, y}$ & 4.76 & - & - & $3 \cdot 13^{y}$ & $4 \cdot 28$ & - & - & $7 \cdot 86^{\star \star \star}$ & 2,1316 \\
\hline Total beverages per week & 37.85 & 15.51 & - & - & $38.68^{x}$ & 13.35 & - & - & $38.87^{x}$ & $16 \cdot 61$ & - & - & $35.85^{y}$ & 15.96 & - & - & $5 \cdot 14^{\star}$ & 2,1316 \\
\hline \multirow{2}{*}{\multicolumn{19}{|c|}{$\begin{array}{l}\text { Sociodemographic variables } \\
\text { Gender }\end{array}$}} \\
\hline & & & & & & & & & & & & & & & & & & \\
\hline \multicolumn{9}{|l|}{ Age $(\%)$} & 53.0 & - & $37 \cdot 6$ & - & $36 \cdot 2$ & & $76 \cdot 26^{\star \star \star}$ & 2 & $80 \cdot 07^{\star \star \star}$ & 2 \\
\hline $18-34$ years & $26 \cdot 7$ & - & $25 \cdot 6$ & - & 23.6 & - & 23.0 & - & $24 \cdot 6$ & - & $31 \cdot 6$ & - & $32 \cdot 1$ & - & $10 \cdot 53^{\star}$ & 4 & $9.55^{\star}$ & 4 \\
\hline $35-49$ years & 32.5 & - & 31.3 & - & 34.5 & - & $35 \cdot 3$ & - & 33.1 & - & 30.3 & - & 29.8 & - & & & & \\
\hline \multirow{2}{*}{\multicolumn{19}{|c|}{ Education (\%) }} \\
\hline & & & & & & & & & & & & & & & & & & \\
\hline Low & 28.1 & - & 21.3 & - & $22 \cdot 2$ & - & 27.5 & - & $30 \cdot 1$ & - & 34.0 & - & $31 \cdot 7$ & - & $16 \cdot 46^{\star \star}$ & 4 & $18 \cdot 35^{\star \star}$ & 4 \\
\hline Middle & $42 \cdot 9$ & - & 45.7 & - & $42 \cdot 1$ & - & 43.7 & - & $45 \cdot 1$ & - & 39.8 & - & 41.0 & - & & & & \\
\hline High & $29 \cdot 0$ & - & 33.0 & - & $35 \cdot 7$ & - & 28.7 & - & 24.8 & - & $26 \cdot 2$ & - & $27 \cdot 4$ & - & & & & \\
\hline \multicolumn{19}{|l|}{$\mathrm{BMI}(\%)$} \\
\hline Underweight $\left(<20 \mathrm{~kg} / \mathrm{m}^{2}\right)$ & 2.5 & - & 3.1 & - & $2 \cdot 2$ & - & 1.4 & - & $1 \cdot 2$ & - & 3.2 & - & $4 \cdot 3$ & - & $36 \cdot 31^{\star \star \star}$ & 6 & $36 \cdot 15^{\star \star \star}$ & 6 \\
\hline Normal weight $\left(20-25 \mathrm{~kg} / \mathrm{m}^{2}\right)$ & 42.9 & - & $47 \cdot 2$ & - & 44.8 & - & $36 \cdot 3$ & - & $38 \cdot 2$ & - & $46 \cdot 7$ & - & 46.4 & - & & & & \\
\hline Overweight $\left(25-30 \mathrm{~kg} / \mathrm{m}^{2}\right)$ & 36.5 & - & $36 . \overline{7}$ & - & 35.5 & - & 38.6 & - & $38 \cdot 4$ & - & 34.2 & - & $35 \cdot 3$ & - & & & & \\
\hline Obese $\left(>30 \mathrm{~kg} / \mathrm{m}^{2}\right)$ & $18 \cdot 1$ & - & $13 \cdot 1$ & - & 17.5 & - & $23 \cdot 8$ & - & $22 \cdot 2$ & - & $15 \cdot 9$ & - & 14.0 & - & & & & \\
\hline
\end{tabular}

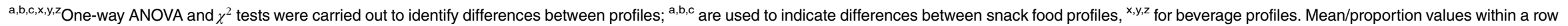
with unlike superscript letters were significantly different, based on Tukey's honest significant difference post hoc test.

${ }^{\star} P<0.05,{ }^{\star \star} P<0.01,{ }^{* \star *} P<0.001$. 
profiles differed significantly on gender, age, education and BMI. For the no-barrier profile we found an overrepresentation of females and higher educated people. The group with a lack-of-opportunity profile was quite similar to the overall respondent population in terms of gender, age and education level. However, compared with those with other profiles, relatively many people with the lack-of-opportunity profile were obese. Respondents with a lack-of-motivation profile were more likely to be male, young and less educated. Daily breakfast and lunch consumption was highest for the no-barrier profile, followed by the lack-of-opportunity profile and the lackof-motivation profile.

Of the 1318 participants, the vast majority (69\%) was classified into the equivalent profiles for both snack categories, meaning that for them patterns of motivation, perceived opportunity and perceived ability were similar for snack foods and beverages.

Relationship between motivation-opportunity-ability profiles and the log odds of choosing low-calorie snacks

To investigate the extent to which the dominant profiles are associated with low-calorie snack choices compared with the MOA factors, we also performed a linear regression analysis in which the MOA factors in Step 2 were substituted for two dummy variables that represented the three dominant profiles. For snack foods, the three identified profiles accounted for $6.6 \%$ (adjusted $6.5 \%$ ) of the variance in the log odds of choosing low-calorie snack foods, compared with 13.2\% (adjusted 12.6\%) for the MOA factors. Thus roughly half of the variance in the log odds of choosing low-calorie snack foods that could be explained by the MOA factors was covered by the identified three dominant MOA profiles.

For beverages, the three identified profiles accounted for $7.5 \%$ (adjusted $7.4 \%$ ) of the variance in the log odds choosing low-calorie beverages, compared with 10.1\% (adjusted $9.5 \%$ ) for the MOA factors. Thus roughly three-quarters of the variance in the log odds of choosing low-calorie beverages that could be explained by the MOA factors was covered by the identified profiles. This means that, in light of implementing effective public health policies, splitting up the population into the three dominant profiles still captures a substantial part of the variance compared with the individual MOA factors.

When using the eight MOA snack food profiles that were constructed by means of a score split, explained variance in the log odds of choosing low-calorie snack foods was similar to the three dominant profiles: $6 \cdot 8 \%$ (adjusted 6.3\%). For the eight MOA beverage profiles, explained variance in the log odds of choosing low-calorie beverages was lower than for the three dominant profiles: $6 \cdot 3 \%$ (adjusted $5 \cdot 8 \%$ ). For tailoring intervention strategies to specific patterns of barriers, using the three dominant profiles thus is preferred over using the eight profile types suggested by the MOA framework.

\section{Discussion}

The present study employed Rothschild's MOA framework $^{(11)}$ and examined the extent to which heterogeneity in barriers regarding the motivation, the perceived opportunity and the perceived ability to choose low-calorie over high-calorie snacks is associated with low-calorie snack choices in real life. The barriers were assessed by means of a survey, together with people's habitual snack consumption, which was measured via the FFQ. To explore generalizability across snack categories, barriers and habitual snack consumption were assessed separately for snack foods and beverages.

The results show that, both for snack foods and beverages, heterogeneity in barriers regarding the motivation, perceived opportunity and perceived ability to choose low-calorie over high-calorie snacks is associated with the proportion of low-calorie snack choices. Recognition of this heterogeneity in barriers adds to the predictive validity for low-calorie snack choices over and above the variance explained by sociodemographic variables. This shows that the MOA framework is a useful and meaningful tool for categorizing barriers for choosing low-calorie over high-calorie snacks. By further distinguishing between the concepts of cognitive and affective attitude, and personal and social norms as aspects of motivation; financial, physical and media aspects of opportunity; and knowledge and skills as aspects of ability, the present study also provides a blueprint to measure these barriers by developing new scales where existing scales were lacking.

In line with previous research on dietary behaviour ${ }^{(56,57)}$, motivation was most strongly associated with low-calorie choices. This confirms that motivation is indispensable when it comes to maintaining and changing snacking behaviour. Of particular importance is a positive affective attitude and strong personal norms regarding low-calorie snacking behaviour, which has been echoed in other studies $^{(58)}$. Cognitive attitude came out as less influential, which is presumably due to a high level of consensus on the functional advantages of low-calorie snacking over high-calorie snacking. This implies that to increase people's motivation to choose low-calorie snacks, it is more important to stress hedonic rather than utilitarian advantages of choosing low-calorie over high-calorie snacks.

A discrepancy between the costs of obtaining highcalorie and low-calorie foods has been repeatedly identified as a key contributor to the obesity problem ${ }^{(39,40,59,60)}$. The present study replicates this by finding that a lack of perceived financial opportunity to choose low-calorie over high-calorie snack foods is associated with lower proportions of low-calorie snack food choices. For beverages no such discrepancy was found, which is likely caused by the high availability of particular cheap low-calorie beverages such as water, tea and coffee.

Perceptions of being able to easily interpret calorie information on snack food packaging increased the proportion of 
low-calorie snack food choices. Previous research indeed found that some people struggle with extracting calorie information from packages, resulting in less understanding of the caloric content of foods and beverages ${ }^{(13)}$. For beverages, it is plausible that no effect of perceived ability on proportion low-calorie choices was found because of the high consumption of water, tea and coffee. When these beverages were removed from analysis, a borderline significant effect of being able to interpret calorie information on beverage packaging on the proportion of low-calorie beverage choices was found. These findings illustrate a widely echoed need for easy-to-interpret information and labelling on packaging to ameliorate ability ${ }^{(61,62)}$.

Overall, barriers regarding the motivation, the perceived opportunity and the perceived ability to choose low-calorie over high-calorie snacks are moderately associated with proportions of low-calorie snack choices at the aggregate level across snack foods and across beverages. When specifically looking at regular and light soft drink choices, for which the only difference is the caloric value, the association between barriers and low-calorie choices is much stronger. This suggests that the origin of the moderate association between barriers and the overall proportion of low-calorie snacks primarily is caused by snack characteristics other than caloric value (e.g. taste). A choice for a low-calorie product (e.g. water or coffee) therefore does not necessarily reflect a preference for lowcalorie beverages, as is the case when choosing for a light soft drink instead of a regular soft drink.

The present study identified three barrier profiles as dominant in the population: the no-barrier profile, the lack-of-opportunity profile and the lack-of-motivation profile. The identification of subgroups with similar barrier characteristics is beneficial for the effectiveness of interventions ${ }^{(14)}$ as, from a public health perspective, tailoring interventions to each individual is infeasible. The dominant profiles were close to identical across the snack foods and beverages contexts, thereby implying that with regard to diminishing barriers, similar intervention strategies can be implemented to stimulate low-calorie choices. Following the MOA framework's rationale, people with a no-barrier profile are best served by educational interventions that maintain their ability. People with a lack-ofopportunity profile will benefit most from marketing interventions that increase opportunity. People with a lack-of-motivation profile will be most likely to change their snacking behaviour when a combination of all three intervention strategies is implemented. Future research should investigate whether tailored intervention strategies are truly more effective than non-tailored interventions.

Confirming the inconclusiveness from earlier research ${ }^{(7,8)}$, no relationship was found between the proportion of low-calorie snack choices and BMI. We did find that people with high proportions of high-calorie snack choices skipped breakfast and lunch more, thereby indicating that a lower caloric intake through meals is compensated with a higher caloric intake through snacks. Another potential confounder for which we did not control is physical activity, which is known to be of influence on the relationship between weight status and eating behaviour ${ }^{(63)}$. Future research is encouraged to take the different definitions of snacking into account and ideally controls for a broader variety of factors that directly or indirectly influence weight status.

There are some limitations that apply to the present study. For measuring motivation, perceived opportunity and perceived ability, validated measures were used as much as possible, and when these were not available new scales were constructed based on earlier qualitative research ${ }^{(13)}$. The results show that for the majority of measures internal consistency and fit were adequate. There were some issues with two oppositely phrased items for the Opportunity measure, however, and therefore they were removed from further analysis. We do think that for assessing Opportunity on a general level, we captured a sufficient part of the construct with the remaining items. Also, for the media measure within Opportunity we used only two items. Future research on barriers for food choices therefore requires further expansion and refinement of these measures.

The behavioural determinants in Rothschild's MOA framework consist of actual motivations, opportunities and abilities. For the present study, however, we used perceptions of opportunities and abilities regarding low-calorie snacking behaviour. This has both practical and theoretical reasons. The practical reason is that it would be burdensome to measure actual opportunity, because it would involve the continuous mapping of different aspects of the food-choice environment (e.g. the amount of advertising, the ratio of low-calorie and high-calorie products). The theoretical reason is that it is plausible that for acceptance of intervention strategies, perceptions of barriers are more important than actual barriers ${ }^{(13)}$. When people do not accept interventions, the risk of reactance towards the intended behaviour increases ${ }^{(64)}$. When people do accept interventions, however, rationalization of behaviour likely occurs $^{(65)}$. Where reactance will impair intervention effectiveness, rationalization will greatly benefit it.

As is argued in literature on dietary behaviour, food choices are multifaceted because they depend on situational, dynamic and complex factors, such as time constraints and social influence ${ }^{(15)}$. The present study applied a framework that encompasses both individual and environment influences on food-choice behaviour and examined these barriers on a more aggregated level. For future research, the results of the present study can be used as a starting point for identifying which barriers are perceived as most prevalent in different food-choice situations.

In the present study, we used an FFQ as it is particularly suitable for eliciting habitual food consumption ${ }^{(47)}$. However, although the questionnaire is widely applied, there are concerns about under-reporting of consumption frequencies ${ }^{(66)}$. For the present study this concern may be less of a problem, as under-reporting of both low-calorie 
and high-calorie snack consumption frequencies does little to change the proportion of low-calorie choices. Furthermore, FFQ are seen as adequately valid dietary assessment measures for aetiological studies ${ }^{(67)}$.

In addition, our classification of the FFQ items into lowcalorie and high-calorie choices is somewhat arbitrary. We used a threshold of $418.4 \mathrm{~kJ}$ ( $100 \mathrm{kcal})$ per portion, so that snacks that are associated with obesity (crisps, cookies, sugar-sweetened beverages) ${ }^{(68)}$ were categorized as highcalorie snacks, and fruits and vegetables were categorized as low-calorie snacks. As a result, individual differences regarding portion sizes were not taken into account, which could partially explain the lack of relationship between weight status and snacking behaviour. The employed classification method is, however, similar to caloric content classification methods in other food-choice research ${ }^{(48,69)}$.

In the classification of snacks, the present study emphasized their caloric values (low-calorie $v$. high-calorie) because an imbalance between energy intake and energy expenditure is the main driver of overweight and obesity ${ }^{(2)}$. In light of responsible snacking choice behaviour, other characteristics than the caloric value of snacks can also be relevant. Snacks with a high nutritional value, for instance, can contribute to a varied and healthy overall dietary pattern. Research on the generalizability of the results to other product characteristics would therefore be valuable.

\section{Conclusions}

Employing Rothschild's MOA framework, the present study contributes to the understanding of unhealthy and irresponsible food-choice behaviour by demonstrating that barriers within motivation, perceived opportunity and perceived ability to choose low-calorie snacks are related to real-life snacking behaviour. In addition, the identification of three dominant barrier profiles (the no-barrier profile, the lack-of-opportunity profile and the lack-ofmotivation profile) provides a strong case for the tailoring of intervention strategies.

Additional research is still needed to examine whether tailoring interventions to barrier profiles does indeed increase the acceptance and subsequently the effectiveness of interventions. Our findings furthermore suggest that, even though measures were carefully selected, improvements in the measurement of barriers for food choice are needed.

\section{Acknowledgements}

Financial support: Funding was provided by the NWO (Netherlands Organization for Scientific Research), project 2100882000. NWO had no role in the design, analysis or writing of this article. Conflict of interest: The authors declare that they have no competing interests. Authorship: C.B. carried out the literature research, analysed the data, and contributed significantly to both the design of the study and the drafting of the manuscript. I.A.v.d.L. contributed substantially to the design of the study and the analysis of the data, and was continuously involved in drafting the manuscript. F.J.v.R. and H.C.M.v.T. contributed substantially to the design of the study and helped drafting the manuscript. All authors read and approved the final manuscript. Ethics of human subject participation: The present study's research protocol was submitted to the Social Science Ethics Committee of the Wageningen University and subsequently approved for fulfilling the Wageningen University code of conduct.

\section{Supplementary material}

To view supplementary material for this article, please visit http://dx.doi.org/10.1017/S1368980015002517

\section{References}

1. Swinburn BA, Sacks G, Hall KD et al. (2011) The global obesity pandemic: shaped by global drivers and local environments. Lancet 378, 804-814.

2. Bleich S, Cutler D, Murray C et al. (2008) Why is the developed world obese? Annu Rev Public Health 29, 273-295.

3. Popkin BM \& Duffey KJ (2010) Does hunger and satiety drive eating anymore? Increasing eating occasions and decreasing time between eating occasions in the United States. Am J Clin Nutr 91, 1342-1347.

4. Gracia A \& Albisu LM (2001) Food consumption in the European Union: main determinants and country differences. Agribusiness 17, 469-488.

5. Ovaskainen ML, Reinivuo H, Tapanainen H et al. (2005) Snacks as an element of energy intake and food consumption. Eur J Clin Nutr 60, 494-501.

6. Shelley JJ (2012) Addressing the policy cacophony does not require more evidence: an argument for reframing obesity as caloric overconsumption. BMC Public Health 12, 1042.

7. Johnson GH \& Anderson GH (2010) Snacking definitions: impact on interpretation of the literature and dietary recommendations. Crit Rev Food Sci Nutr 50, 848-871.

8. Gregori D, Foltran F, Ghidina M et al. (2011) Understanding the influence of the snack definition on the association between snacking and obesity: a review. Int J Food Sci Nutr 62, 270-275.

9. Hartmann C, Siegrist M \& van der Horst K (2013) Snack frequency: associations with healthy and unhealthy food choices. Public Health Nutr 16, 1487-1496.

10. Zizza C, Siega-Riz AM \& Popkin BM (2001) Significant increase in young adults' snacking between 1977-1978 and 1994-1996 represents a cause for concern! Prev Med 32, 303-310.

11. Rothschild ML (1999) Carrots, sticks, and promises: a conceptual framework for the management of public health and social issue behaviors. J Mark 63, 24-37.

12. Elbel B (2011) Consumer estimation of recommended and actual calories at fast food restaurants. Obesity (Silver Spring) 19, 1971-1978.

13. Bos C, Van der Lans IA, Van Rijnsoever FJ et al. (2013) Understanding consumer acceptance of intervention strategies for healthy food choices: a qualitative study. $B M C$ Public Health 13, 1073.

14. Gordon R, McDermott L, Stead M et al. (2006) The effectiveness of social marketing interventions for health 
improvement: what's the evidence? Public Health 120, 1133-1139.

15. Sobal J \& Bisogni CA (2009) Constructing food choice decisions. Ann Behav Med 38, Suppl. 1, S37-S46.

16. Ajzen I \& Timko C (1986) Correspondence between health attitudes and behavior. Basic Appl Soc Psychol 7, 259-276.

17. Rosenstock IM, Strecher VJ \& Becker MH (1988) Social learning theory and the health belief model. Health Educ Behav 15, 175-183.

18. Greene GW, Rossi SR, Rossi JS et al. (1999) Dietary applications of the stages of change model. J Am Diet Assoc 99, 673-678.

19. Crites SL, Fabrigar LR \& Petty RE (1994) Measuring the affective and cognitive properties of attitudes - conceptual and methodological issues. Pers Soc Psychol Bull 20, 619-634.

20. Geeroms N, Verbeke W \& Van Kenhove P (2008) Consumers' health-related motive orientations and ready meal consumption behaviour. Appetite 51, 704-712.

21. Conner M, Norman P \& Bell R (2002) The theory of planned behavior and healthy eating. Health Psychol 21, 194-201.

22. Satia JA, Kristal AR, Curry S et al. (2001) Motivations for healthful dietary change. Public Health Nutr 4, 953-959.

23. Mai R \& Hoffmann S (2012) Taste lovers versus nutrition fact seekers: how health consciousness and self-efficacy determine the way consumers choose food products. $J$ Consum Behav 11, 316-328.

24. Hollywood LE, Cuskelly GJ, O'Brien M et al. (2013) Healthful grocery shopping. Perceptions and barriers. Appetite 70, 119-126.

25. Catlin TK, Simoes EJ \& Brownson RC (2003) Environmental and policy factors associated with overweight among adults in Missouri. Am J Health Promot 17, 249-258.

26. Swinburn B, Egger G \& Raza F (1999) Dissecting obesogenic environments: the development and application of a framework for identifying and prioritizing environmental interventions for obesity. Prev Med 29, 563-570.

27. Rozin (2011) Nudge to nobesity I: minor changes in accessibility decrease food intake. Judgm Decis Mak 6, 323-332.

28. Dayan (2011) Nudge to nobesity II: menu positions influence food orders. Judgm Decis Mak 6, 333-342.

29. Boehmer TK, Hoehner CM, Deshpande AD et al. (2007) Perceived and observed neighborhood indicators of obesity among urban adults. Int J Obes (Lond) 31, 968-977.

30. Lucan SC \& Mitra N (2012) Perceptions of the food environment are associated with fast-food (not fruit-andvegetable) consumption: findings from multi-level models. Int J Public Health 57, 599-608.

31. Gustafson AA, Sharkey J, Samuel-Hodge CD et al. (2011) Perceived and objective measures of the food store environment and the association with weight and diet among low-income women in North Carolina. Public Health Nutr 14, 1032-1038.

32. Giskes K, Van Lenthe FJ, Brug J et al. (2007) Socioeconomic inequalities in food purchasing: the contribution of respondent-perceived and actual (objectively measured) price and availability of foods. Prev Med 45, 41-48.

33. Giesen JCAH, Havermans RC, Nederkoorn C et al. (2012) Impulsivity in the supermarket. Responses to calorie taxes and subsidies in healthy weight undergraduates. Appetite 58, 6-10.

34. Epstein LH, Dearing KK, Roba LG et al. (2010) The influence of taxes and subsidies on energy purchased in an experimental purchasing study. Psychol Sci 21, 406-414.

35. Dressler H \& Smith C (2013) Food choice, eating behavior, and food liking differs between lean/normal and overweight/obese, low-income women. Appetite 65, 145-152.

36. Hartman H, Wadsworth DP, Penny S et al. (2013) Psychosocial determinants of fruit and vegetable consumption among students in a New Zealand university. Results of focus group interviews. Appetite 65, 35-42.

37. Neumark-Sztainer D, Story M, Perry C et al. (1999) Factors influencing food choices of adolescents: findings from focus-group discussions with adolescents. J Am Diet Assoc 99, 929-936.

38. Lobstein T \& Dibb S (2005) Evidence of a possible link between obesogenic food advertising and child overweight. Obes Rev 6, 203-208.

39. Kirk SFL, Penney TL \& McHugh TLF (2010) Characterizing the obesogenic environment: the state of the evidence with directions for future research. Obes Rev 11, 109-117.

40. Giskes K, van Lenthe F, Avendano-Pabon M et al. (2011) A systematic review of environmental factors and obesogenic dietary intakes among adults: are we getting closer to understanding obesogenic environments? Obes Rev 12, e95-e106.

41. Baranowski T, Cullen KW, Nicklas $\mathrm{T}$ et al. (2003) Are current health behavioral change models helpful in guiding prevention of weight gain efforts? Obes Res 11, Suppl. 2, 23S-43S.

42. Brug J (2008) Determinants of healthy eating: motivation, abilities and environmental opportunities. Fam Pract 25, I50-I55.

43. Van Trijp HCM, Brug J \& Van der Maas R (2005) Consumer determinants and intervention strategies for obesity prevention. In Food, Diet and Obesity, pp. 331-355 [DJ Mela, editor]. Cambridge: Woodhead Publishing Ltd.

44. Krukowski RA, McSweeney J, Sparks C et al. (2012) Qualitative study of influences on food store choice. Appetite 59, 510-516.

45. Parker D, Manstead ASR \& Stradling SG (1995) Extending the theory of planned behaviour: the role of personal norm. Br J Soc Psychol 34, 127-138.

46. Sheeshka JD, Woolcott DM \& Mackinnon NJ (1993) Social cognitive theory as a framework to explain intentions to practice healthy eating behaviors 1. J Appl Soc Psychol 23, $1547-1573$.

47. Cade J, Thompson R, Burley V et al. (2002) Development, validation and utilisation of food-frequency questionnaires a review. Public Health Nutr 5, 567-587.

48. Kocken PL, van Kesteren NM, Buijs G et al. (2015) Students' beliefs and behaviour regarding low-calorie beverages, sweets or snacks: are they affected by lessons on healthy food and by changes to school vending machines? Public Health Nutr 18, 1545-1553.

49. Rosseel $\mathrm{Y}$ (2012) lavaan: an R package for structural equation modeling. J Stat Software 48, 1-36.

50. Hair JF, Black WC, Babin BJ et al. (2010) Multivariate Data Analysis: A Global Perspective. Upper Saddle River, NJ: Pearson Education.

51. Nunnally JC (1978) Psychometric Theory. New York: McGraw-Hill.

52. Fornell C \& Larcker DF (1981) Evaluating structural equation models with unobservable variables and measurement error. J Mark Res 18, 39-50.

53. Bland JM \& Altman DG (2000) The odds ratio. BMJ 320, 1468.

54. Tukey JW (1962) The future of data analysis. Ann Math Stat 33, $1-67$.

55. Charrad M, Ghazzali N, Boiteau V et al. (2014) NbClust: an $\mathrm{R}$ package for determining the relevant number of clusters in a data set. J Stat Software 61, 1-36.

56. Hearty A, McCarthy S, Kearney J et al. (2007) Relationship between attitudes towards healthy eating and dietary behaviour, lifestyle and demographic factors in a representative sample of Irish adults. Appetite 48, 1-11.

57. Dibsdall L, Lambert N, Bobbin R et al. (2003) Low-income consumers' attitudes and behaviour towards access, 
availability and motivation to eat fruit and vegetables. Public Health Nutr 6, 159-168.

58. Paisley CM \& Sparks P (1998) Expectations of reducing fat intake: the role of perceived need within the theory of planned behaviour. Psychol Health 13, 341-353.

59. Drewnowski A \& Darmon N (2005) Food choices and diet costs: an economic analysis. J Nutr 135, 900-904.

60. Drewnowski A \& Specter SE (2004) Poverty and obesity: the role of energy density and energy costs. Am J Clin Nutr $\mathbf{7 9}$, 6-16.

61. Magnusson RS (2010) Obesity prevention and personal responsibility: the case of front-of-pack food labelling in Australia. BMC Public Health 10, 662.

62. Grunert KG \& Wills JM (2007) A review of European research on consumer response to nutrition information on food labels. J Public Health 15, 385-399.

63. Duval K, Strychar I, Cyr M-J et al. (2008) Physical activity is a confounding factor of the relation between eating frequency and body composition. Am J Clin Nutr 88, 1200-1205.

64. Brehm JW (1966) A Theory of Psychological Reactance. Oxford: Academic Press.

65. Laurin K, Kay AC \& Fitzsimons GJ (2012) Reactance versus rationalization: divergent responses to policies that constrain freedom. Psychol Sci 23, 205-209.

66. Bingham SA, Luben R, Welch A et al. (2003) Are imprecise methods obscuring a relation between fat and breast cancer? Lancet 362, 212-214.

67. Byers T (2001) Food frequency dietary assessment: how bad is good enough? Am J Epidemiol 154, 1087-1088.

68. Cohen DA, Sturm R, Scott M et al. (2010) Not enough fruit and vegetables or too many cookies, candies, salty snacks, and soft drinks? Public Health Rep 125, 88-95.

69. Bandini LG, Vu D, Must A et al. (1999) Comparison of highcalorie, low-nutrient-dense food consumption among obese and non-obese adolescents. Obes Res 7, 438-443. 